\title{
Biomedical significance of endothelial cell specific growth factor, angiopoietin
}

\author{
Gou Young Koh ${ }^{1,2}$, Injune Kim ${ }^{1}$, Hee Jin Kwak', \\ Mi-Jeong Yun ${ }^{1}$ and Jae Chan Leem ${ }^{1}$ \\ ${ }^{1}$ National Creative Research Initiatives Center for Endothelial Cells
and Division of Molecular and Life Sciences, Pohang University of
Science and Technology, Pohang, 790-784, Republic of Korea
${ }^{2}$ Corresponding author: Tel, +82-54-279-2286;
Fax, +82-54-279-8366; E-mail, gykoh@postech.ac.kr
}

Accepted 5 February 2002

Abbreviations: VEGF, vascular endothelial cell growth factor; RTK, receptor tyrosine kinases; Tie2, tyrosine kinase with immunoglobulin and epidermal growth factor homology domains 2; Ang1, angiopoietin-1; Ang2, angiopoietin-2; Angll, angiotensin II; PI 3'kinase, phosphatidylinositol 3'-kinase, STAT, signal transducers and activators of transcription; HSC, hematopoietic stem cells

\section{Overview}

Until recently, vascular endothelial growth factor (VEGF) was the only growth factor proven to be specific and critical for blood vessel formation. Other longknown factors, such as the fibroblast growth factors (FGFs), platelet-derived growth factor, or transforming growth factor-beta, had profound effects in endothelial cells. But such factors were nonspecific, in that they could act on many other cells, and it seemed unlikely that these growth factors would be effective targets for treatment of endothelial cell diseases. A recently discovered endothelial cell specific growth factor, angiopoietin, has greatly contributed to our understanding of the development, physiology, and pathology of endothelial cells (Davis et al., 1996; Yancopoulos et al., 2000). The recent studies that identified and characterized the physiological and pathological roles of angiopoietin have allowed us to widen and deepen our knowledge about blood vessel formation and vascular endothelial function. Therefore, in this review, we describe the biomedical significance of these endothelial cell growth factors, the angiopoietins, in the vascular system under normal and pathological states.

Keywords: angiopoietin-1, angiopoietin-2, Tie2

Identification of the Tie2 receptor and angiopoietin The transmembrane protein kinases serve as signaling receptors for a variety of polypeptide ligands, eliciting such diverse responses as cell survival, proliferation and differentiation from many cell types and tissues (van der Geer et al., 1994). Receptor tyrosine kinases (RTKs) have the ability to interact with different ligands and bring about various cellular responses. One type of RTK is the tyrosine kinase with immunoglobulin and epidermal growth factor homology domains (Tie) receptors (Dumont et al., 1993; Mustonen et al., 1995). Tie2 is expressed predominantly on endothelial cells, hematopoietic cells, or their embryonic precursors, and it is required for normal vascular development (Sato et al., 1995). Functional disruption of Tie2 in transgenic mice results in embryonic lethality by day E9.5 to 10.5 , with effects on the microvasculature resulting in reduced numbers of endothelial cells, and abnormalities of vascular morphogenesis and hematopoiesis (Sato et al., 1995). Thus, Tie2 is critical for angiogenesis and hematopoiesis during development. This fact makes it important to identify and clone ligands that may activate this receptor.

The initial identification of potential ligands for the Tie2 receptor was accomplished by a fairly conventional route, parallel to that taken for the identification of ligands for many other "orphan" receptors. Specifically, a probe molecule containing the ectodomain of Tie2 was coupled to the surface of a BIAcore sensor chip and used to screen conditioned media from a variety of cell lines for binding activity specific for Tie2. Using this strategy, Davis et al. found the ligand for Tie2, namely angiopoietin-1 (Ang1) (Davis et al., 1996). Ang1 contains 498 amino acids, including an amino-terminal secretory signal sequence (Figure 1). Human and mouse Ang1 are $97.6 \%$ identical. Two regions within the coding sequence display homology to known proteins (Figure 1). The amino-terminal region, consisting of residues $100-280$, is weakly related with myosin and its relatives, in the regions of these proteins where they are known to possess coiled-coil quaternary structure. The second region, consisting of residues $280-498$, has strong similarity with the carboxyterminal domain of fibrinogen. Ang1 is a multimer, held together by coiled-coil structures and disulfide crosslinks. Recombinant Ang1 is a $70-\mathrm{kDa}$ secretory glycoprotein that binds to the Tie2 receptor with a $\mathrm{Kd}$ of approximately $3.7 \mathrm{nM}$, and induces tyrosine phosphorylation of Tie2 in endothelial cells (Davis et al., 1996).

Complementary DNAs encoding angiopoietin-2 (Ang2) were isolated by low stringency screening of a cDNA library by using Ang1 cDNA as a probe (Maisonpierre et al., 1997). Ang2 contains 496 amino acids and has a secretory signal sequence (Figure 1). Human and mouse Ang2 are $85 \%$ identical and approximately $60 \%$ identical 


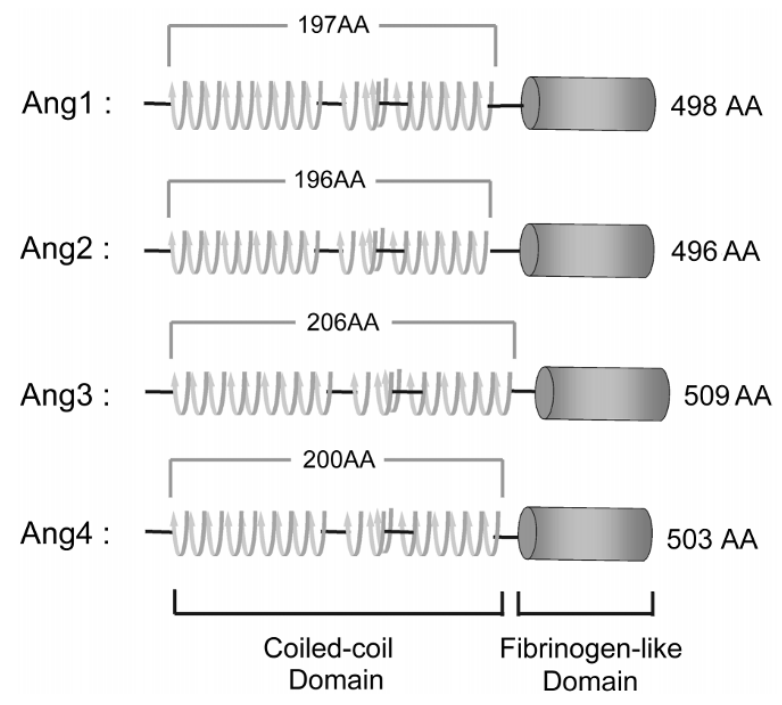

Figure 1. The angiopoietin family, as it is currently known. These structurally similar ligands have a coiled-coil domain and the fibrinogen-like domain.

to Ang1. Like Ang1, Ang2 has an amino-terminal coiledcoil domain and a carboxy-terminal fibrinogen-like domain. Ang1 and Ang2 have similar binding affinities for Tie2. Ang2 acts as an antagonist of Tie2 through inhibition of Ang1-induced phosphorylation of Tie2 (Maisonpierre et al., 1997) (Figure 2). Mouse angiopoietin-3 (Ang3) and human angiopoietin-4 (Ang4) were identified through low stringency hybridization screening with Ang1 and Ang2 cDNAs (Valenzuela et al., 1999). Ang3 and Ang4 are probably interspecies orthologs (Figure 1). Ang4 phosphorylates Tie2, while Ang3 inhibits Ang1-induced phosphorylation of Tie2 (Valenzuela et al., 1999) (Figure 2). Although several angiopoietin-related proteins have recently been identified, they do not bind to Tie2 (Kim et al., 1999; Kim et al., 2000a). There may be more unidentified angiopoietinlike proteins that can specifically bind to Tie2.

\section{Alternative splicing of Ang1 and Ang2}

In studying megakaryopoiesis, 3 alternatively spliced species of Ang-1 mRNA (1.3 kb, $0.9 \mathrm{~kb}$, and $0.7 \mathrm{~kb}$ ) were identified, in addition to the full-length Ang-1 (1.5 kb) (Huang et al., 2000). The proteins expressed by the 1.5- and 0.9-kb transcripts bind strongly to Tie2, whereas the protein from the 1.3-kb isoform does not. Full-length Ang1, but not the 1.3-kb and 0.9-kb isoforms, induces tyrosine phosphorylation (Huang et al., 2000). These data suggest that the1.3-kb and 0.9-kb encoded isoforms could serve as dominant negative molecules for full-length Ang1.

The major form of Ang2 contains 496 amino acids. Alternative exon splicing of Ang2 produces an alternative mRNA encoding 443 amino acids (Kim et al., 2000e). Like Ang2, Ang2 ${ }_{443}$ is secreted as a glycosylated homodimeric protein. Ang2 ${ }_{443}$ binds to the Tie2, but does not induce Tie2 phosphorylation. Pre-occupation of Ang2 443 on Tie2 inhibits Ang1 or Ang2 binding and inhibits Ang1-

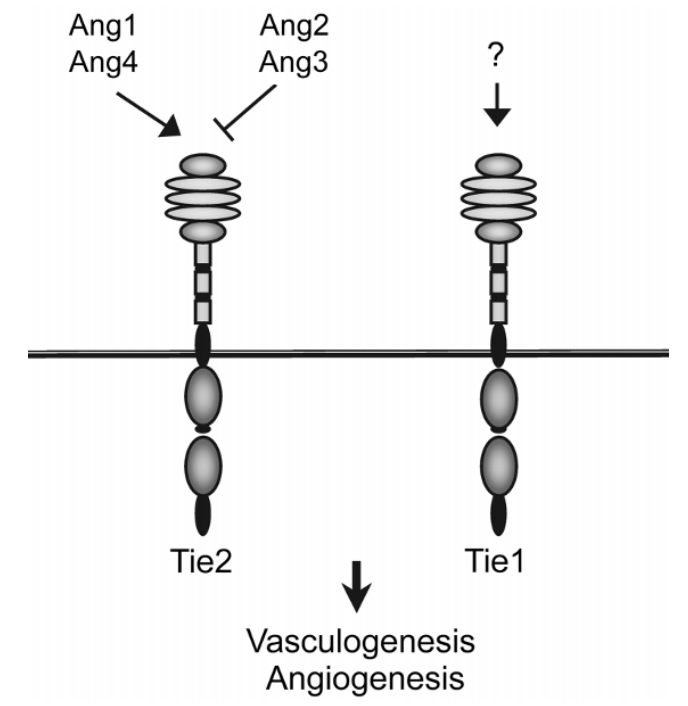

Figure 2. Tie2 and Tie1 receptors in endothelial cells. The extracellular region of the Tie receptors consists of immunoglobulin (Ig)-like domains, epidermal growth factor (EGF)-like cysteine repeats, and fibronectin type III homology domains. In the intracellular region of the Tie receptors, the tyrosine kinase domains are interrupted by kinase inserts. Ang1 and Ang4 act as functional agonists of Tie2 through phosphorylation of Tie2, while Ang2 and Ang3 act as functional antagonists of Tie2 through inhibition of Ang1-induced phosphorylation of Tie2. These opposing actions of angiopoietins regulate vasculogenesis and angiogenesis. However, ligands for Tie1 have not been identified.

induced phosphorylation. Expression of $A n g 2_{443}$ mRNA is detectable in primary endothelial cells, several nonendothelial tumor cell lines, and primary tumor tissues. Interestingly, two cervical carcinoma cell lines express levels of $A n g 2_{443}$ mRNA and protein that are relatively higher than other cell types studied (Kim et al., 2000e). Macrophages express mainly Ang2 mRNA, but the expression of $A n g 2_{443}$ mRNA is temporarily upregulated during macrophage differentiation. These results suggest that Ang $2_{443}$ is a functional antagonist of Ang1 and could be an important regulator of angiogenesis during some tumorigenic and inflammatory processes.

\section{Biological roles of Ang1 and Ang2 during embryonic development}

Targeted gene inactivation of Ang1 causes embryonic lethality as a result of defective modeling of primitive vascular plexus and lack of perivascular cells (Suri et al., 1996). Overall, targeted gene inactivation of Ang1 resulted in phenotypes similar to Tie2 knockout animals. These results suggest that Ang1 recruits and sustains peri-endothelial support cells and is needed for the maturation of blood vessels during embryonic development. Overexpression of Ang2 during development produced phenotypes very similar to those observed in Ang1 knockout animals (Maisonpierre et al., 1997). These data suggest that Ang2 disrupts blood vessel formation in the developing embryo by antagonizing the effects of 
Ang1 on Tie2 (Suri et al., 1996; Maisonpierre et al., 1997). However, an analysis and characterization of targeted gene inactivation of Ang2 is warranted for understanding of the exact role of Ang2 during development.

\section{Regulation of Ang1 and Ang2 expression}

While Ang1 mRNA is mainly expressed in periendothelial cells, including vascular smooth muscle (Kim et al., 2000c), Ang2 mRNA is selectively expressed in endothelial cells in the adult tissues that undergo vascular remodeling, such as ovary, uterus, and placenta (Maisonpierre et al., 1997). To date, the regulation of Ang1 mRNA expression is unknown, but we do have some information about the regulation of Ang2 (Figure 3).

Hypoxia is a fundamental angiogenic stimulus in a number of physiological and pathological situations associated with neovascularization. The VEGF gene has been shown to contain specific hypoxia-responsive elements and is upregulated in response to low oxygen tensions in a variety of physiological and pathological situations. Ang2, but not Ang1, expression is also increased by hypoxia in macro- and micro-vascular endothelial cells (Mandriota et al., 1998; Oh et al., 1999). This phenomenon is apparently specific to these cells, because Ang2 expression levels were not significantly altered by hypoxia in smooth muscle cells. These findings identify Ang2, in addition to VEGF, as another hypoxia-inducible angiogenic factor and a potentially important component in the regulation of neovascularization in ischemic tissues. Hypoxia also upregulates Ang2 expression in vivo (Mandriota et al., 2000). In ischemic rat dorsal skin flaps or in the brain of rats maintained under conditions of hypoxia, Ang2 mRNA is upregulated, whereas expression of Ang1 is unchanged (Mandriota et al., 2000). These findings show that upregulation of Ang2 by hypoxia occurs widely in endothelial cells in vivo. However, the molecular structure of the hypoxia-responsive element in the promoter region of Ang2 has not yet been identified.

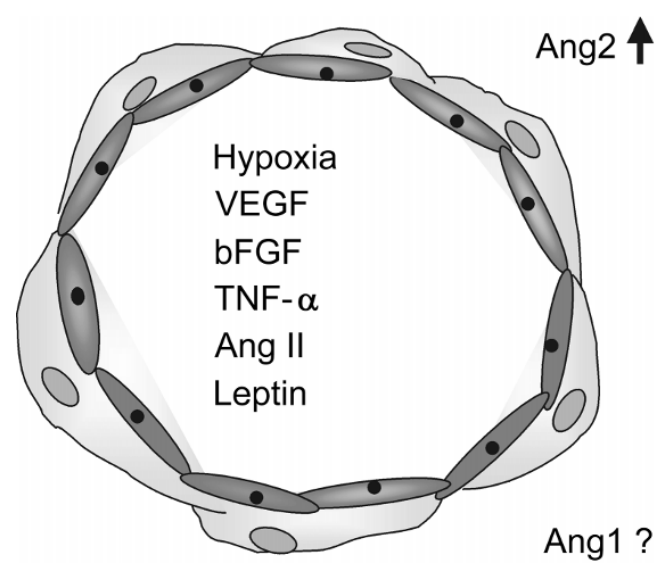

Figure 3. Regulation of Ang1 and Ang2 expression. Hypoxia, VEGF, bFGF, TNF- $\alpha$, angiotensin II and leptin upregulate Ang2 expression. However, the regulation of Ang1 expression is unknown.
VEGF and bFGF increase Ang2, but not Ang1, expression in microvascular endothelial cells, indicating that upregulation of Ang2 might be a common pathway by which different angiogenic inducers act (Mandriota et al., 1998; Oh et al., 1999). Pharmacological studies indicated that tyrosine kinase, mitogen-activated protein kinase, and protein kinase $\mathrm{C}$-dependent pathways play a crucial role in VEGF-induced Ang2 expression (Oh et al., 1999). Further studies to explore the signaling pathway underlying the VEGF-induced Ang2 mRNA expression will be needed.

TNF- $\alpha$, a well-known proinflammatory cytokine, increases Ang2 expression, at least in part, through intracellular $N F-\kappa B$ activation in human umbilical vein endothelial cells (Kim et al., 2000f). Angiogenesis is also an essential process during inflammation. However, it is unknown whether Ang2 is involved during inflammation. In fact, disruption of preexisting blood vessels is an initial process in inflammatory angiogenesis. Ang2 binds to the Tie2 receptor, but does not induce its phosphorylation. In addition, pre-occupation of Ang2 on Tie2 inhibits Ang1induced phosphorylation. Ang1-induced Tie2 phosphorylation is an essential process for vasculogenesis and maintaining vascular endothelial integrity. Induction of Ang2 can deteriorate the integrity of preexisting vasculature by inhibiting Ang1-induced Tie2 phosphorylation. Therefore, TNF- $\alpha$-induced inflammatory angiogenesis might be facilitated by the induction of Ang2.

Leptin is a cytokine secreted by adipocytes. Leptin regulates adipose tissue mass by decreasing appetite and elevating the expenditure of metabolic energy. Recently, it was shown that leptin increases the expression of Ang2 in adipose tissue without a concomitant increase in VEGF (Cohen et al., 2001). Induction of Ang2 occurred in an autocrine manner, and the induction of Ang2 coincided with initiation of apoptosis in adipose endothelial cells. These results suggest that induction of Ang2 by leptin in adipose cells is one of the events leading to adipose tissue regression through vascular regression.

Angiotensin II (Angll) is known to play a key role in remodeling of the heart and blood vessels after myocardial infarction. Recently, two groups reported that Angll induces Ang2 expression without affecting Ang1 in cardiac and retinal microvascular endothelial cells (Fujiyama et al., 2001; Otani et al., 2001). In addition, Angll increases expression of Ang2 in vivo in a rat corneal neovascularization model (Otani et al., 2001). These findings suggest that Angll has a substantial effect in promoting pathologic angiogenesis in diabetic retinopathy and other ischemic neovascular diseases. The precise role of Angll induction of Ang2 in pathologic angiogenesis remains to be determined.

Ang1/Tie2 signaling in endothelial cells

A multimeric form of Ang1 induce the phosphorylation of 
Tie2. Phosphorylated Tie2 interacts cytoplasmically with Grb2, Grb7, Grb14, the protein tyrosine phosphatase Shp2, and the p85 subunit of phosphatidylinositol 3'kinase (PI 3'-kinase) via their $\mathrm{SH} 2$ domains (Jones et al., 1999) (Figure 4). Association between p85 and Tie2 results in PI 3'-kinase activation and subsequent induction of the serine-threonine kinase Akt. (Kontos et al., 1998). We reported that Ang1 induced endothelial cell survival through this PI 3'-kinase/Akt signaling pathway (Kim et al., 2000c). In addition, Ang1 induced endothelial cell sprouting through the activation of $\mathrm{PI}$ 3-kinase and focal adhesion kinase (Kim et al., 2000b). Thus, Tie2, PI 3'-kinase, Akt, and focal adhesion kinase are crucial elements in the signal transduction pathway leading to survival and migration in endothelial cells (Figure 4). Phosphorylated Tie2 also interacts with Dok-R/Dok-2, leading to activation of Dok-R/Dok-2 (Jones et al., 1998). Phosphorylated Dok-R interacts with rasGAP, Nck, and Crk (Jones et al., 1998) (Figure 4). These signaling molecules may be involved in cell migration and proliferation, organization of the cytoskeleton, and regulation of Ras signaling. Recently, it was shown that Dok-R/ Dok-2 is responsible for the recruitment of Nck and p21activating kinase (Pak/Pak1) to the activated receptor (Master et al., 2001). Localization of this Dok-R-Nck-Pak complex to the activated Tie2 at the cellular membrane is coincident with activation of Pak kinase (Master et al., 2001) (Figure 4). This signal transduction pathway may be involved in Ang1-mediated migration in endothelial cells.

Recently, the Bmx tyrosine kinase was identified to be the first intracellular tyrosine kinase that is regulated by Tie2 and relatively specific for the arterial endothelium in solid tissues (Rajantie et al., 2001). Since the Bmx tyrosine kinase is involved in endothelial cell adhesion and migration, it is possible that Bmx provides the Tie2 receptor a signal amplifier and a link to the cytoskeleton and cell adhesion machinery (Figure 4). Thus, Tie2-Bmx activation may induce a tightly adherent endothelial cell phenotype in arteries, where high blood flow and shear stress forces operate. The functional significance and possible route of $\mathrm{Bmx}$ activation by $\mathrm{Tie} 2$ remain to be determined.

The signal transducers and activators of transcription (STATs) were also found to be potential targets of Tie2 activation (Korpelainen et al., 1999). Phosphorylated Tie2 activates STAT3 and STAT5 (Korpelainen et al., 1999). Since STAT3 and/or STAT5 are known to be involved in the regulation of cell proliferation, differentiation, migration, and survival in many biological systems, it is possible that some of the Tie2 functions in endothelial cells may be controlled through STAT pathway (Figure 4).

Ang1 and Ang2 in the reproductive system

In the female reproductive system, angiogenesis is active

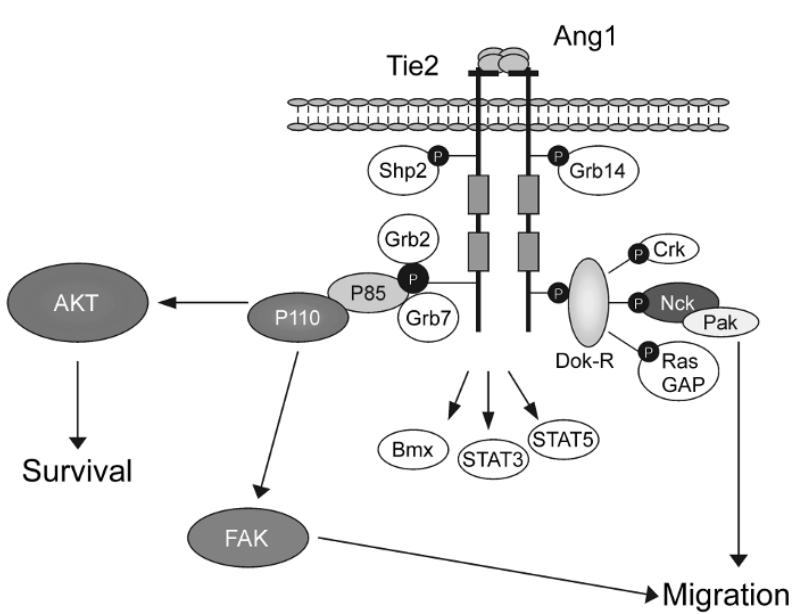

Figure 4. Upon Ang1 binding to Tie2, the intracellular domain of Tie2 is phosphorylated. The p85 subunit of PI 3'-kinase associates with the phosphorylated Tie2 receptor, resulting in stimulation of PI 3'-kinase. Subsequent activation of the serine/threonine kinase Akt correlates with an increase in cell survival. Alternatively, PI 3'-kinase activity is coincident with focal adhesion kinase activation and cell migration. Phosphorylated Tie2 also interacts with Dok-R, leading to activation of rasGAP, Nck, and Crk. These signaling molecules may be involved in cell migration. Phosphorylated Tie2 also activates STAT3 and STAT5, which may be involved in the differentiation of endothelial cells.

during follicular development, corpus luteum formation, and uterine endometrial proliferation. At the stage of corpus luteum formation, the amount of Ang2 is similar to that of Ang1. But during luteolysis, Ang2 was overexpressed and VEGF expression was downregulated, which resulted in vessel regression (Goede et al., 1998). These changes in expression levels during the ovarian cycle show that Ang1 and VEGF promote angiogenesis and vessel maturation, whereas Ang2 induces vessel regression. In the endometrium of women with abnormal uterine bleeding, Ang1 expression is downregulated (Geva et al., 2000). This supports the idea that Ang1 has a role in vessel maturation and maintenance.

In pregnancies with intrauterine growth retardation (IUGR), there is reduced or absent end-diastolic flow velocity, and Ang2 expression is reduced (Dunk et al., 2000). This result suggests that Ang2 is required in the initiation of angiogenesis for placental vessel formation. When fetal trophoblasts invade the maternal arteries of the uterus during implantation, the invading trophoblasts express Ang2, while fetal and maternal endothelial cells express Tie2 receptors (Goldman-Wohl et al., 2000). This suggests that Ang2 on endovascular invasive trophoblasts acts on maternal endothelial cells and triggers vessel remodeling, by acting as an antagonist of Ang1. Thus, the angiopoietin-Tie2 system is important in the development of the utero/fetoplacental circulation as regulators of trophoblast behavior.

\section{Ang1 and Tie2 in hematopoiesis}


It is known that the Tie2 receptor is expressed not only by endothelial cells but also by hematopoietic stem cells (HSCs), indicating another possible role of Ang1 and Tie2 in hematopoiesis (Iwama et al., 1993). In fact, Tie2 deficient mice show severely impaired hematopoiesis (Sato et al., 1995). In addition, Takakura et al. investigated that soluble Tie2 receptor inhibited hematopoiesis in para-aortic splanchnopleural mesoderm explant culture (Takakura et al., 1998). In addition, Ang1 induced adhesion of Tie2-expressing HSCs to fibronectin leads to hematopoietic proliferation (Takakura et al., 1998). Moreover, Tie2 on HSCs also may be critical in the interaction of these cells with endothelial cells (Phillips et al., 2000; Takakura et al., 2000). In fact, HSCs closely adhere to endothelial cells at several sites in the embryo. Furthermore, it has been found that HSCs produce Ang1, suggesting that HSCs can promote the migration of endothelial cells and establish the hematopoietic environment (Takakura et al., 2000). Recently, it was found that Ang1, together with VEGF, stimulates postnatal hematopoiesis through extramedullary recruitment of bone marrow-derived HSCs and circulating endothelial precursor cells. Sustained expression of Ang1 and VEGF resulted in splenomegaly, which indicates shift in hematopoiesis to extramedullary sites, with relocalization of HSCs to other hematopoietic environments, such as spleen (Dias et al., 2001). This recruitment of HSCs by angiogenic factors may explain the shift of hematopoiesis site from fetal liver to bone marrow or spleen.

\section{Involvement of Ang1 and Ang2 in tumors}

Angiogenesis and vasculogenesis are associated with tumor growth. Thus, the role of angiopoietins in tumors has been investigated. High levels of Ang2 mRNA are observed in highly vascularized tumors, such as glioblastoma, Kaposi's sarcoma, cutaneous angiosarcoma, hemangioma, thyroid tumors and gastric and colorectal cancer (Stratmann et al., 1998; Bunone et al., 1999; Yoshida et al., 1999; Brown et al., 2000; Etoh et al., 2001; Yu et al., 2001). Ang2 is also abundantly expressed, not only in tumor cells, but also in the endothelial cells of sprouting microvessels of solid tumors (Stratmann et al., 1998; Bunone et al., 1999; Holash et al., 1999). Consistently, histological analyses of tumor specimens indicate that Ang2 expression plays a key role in tumor angiogenesis, both at early and later stages of vascular activation (Bunone et al., 1999; Holash et al., 1999; Zagzag et al., 1999). Thus, Ang2 probably helps tumor vessel formation. However, the observation that Ang2 production is also elevated at the sites of vascular regression where VEGF is not abundant led to the hypothesis that the role of Ang2 in sprouting angiogenesis is highly dependent on the presence of VEGF (Stratmann et al., 1998; Holash et al., 1999). In the presence of VEGF, Ang2, by antagonizing the stabilizing or antiapoptotic effects of Ang1 on endothelial cells, promotes migration, proliferation, and sprouting of endothelial cells. By comparison, in the absence of VEGF, Ang2 may lead to endothelial cell apoptosis and vascular regression (Stratmann et al., 1998; Bunone et al., 1999; Holash et al., 1999).

Ang2 at high concentration can be an apoptosis survival factor for endothelial cells through the activation of PI3'-kinase and Akt (Kim et al., 2000d). This suggests that Ang2 can be a promoter in tumor vessel formation in tumor formation. Thus, the pathological role of Ang2 is more complex than previously recognized: it has various effects on Tie2 receptor signaling, depending on local conditions.

In contrast to Ang2, the expression of Ang1 is not high in most tumors (Hayes et al., 2000). In fact, Ang1 overexpression in a breast tumor cell line led to retardation of tumor growth in xenograft model (Hayes et al., 2000). These data suggest that Ang1 may inhibit tumor growth, presumably by inhibiting tumor angiogenesis. However, in a xenograft model with human cervical carcinoma HeLa cells, introduction of Ang1 antisense RNA led to retardation in tumor cell growth and tumor angiogenesis in nude mice (Shim et al., 2001). This result indicates that Ang1 is involved with tumor angiogenesis as a proangiogenic factor. Thus, whether Ang1 is an inducible or inhibitory growth factor in tumor angiogenesis depends on tumor type. Further study is required to clarify the role of Ang1 in tumor formation and maintenance.

Interestingly, Tie2 is also strongly expressed in endothelial cells of Kaposi's sarcoma, cutaneous angiosarcoma, colorectal cancer, thyroid tumor, hemangioma, and non-small cell lung carcinomas (Bunone et al., 1999; Takahama et al., 1999; Brown et al., 2000; Etoh et al., 2001; Yu et al., 2001). In fact, administration of soluble Tie2 inhibited the growth of primary tumors and tumor metastases (Lin et al., 1998). Similarly, we recently observed that administration of Tie2 inhibitor BSF 466895.C2 inhibited melanoma tumor growth (unpublished observation). These data suggest that Tie2 activation may have an important role in tumor angiogenesis. However, it is not known how Ang1 or Ang2 are involved with Tie2 activation in tumor angiogenesis.

\section{Therapeutic Angiogenesis and Vaculogenesis with Ang1}

Blood vessels form through two distinct processes, vasculogenesis and angiogenesis (Figure 1) (Risau, 1997; Carmeliet, 2000). In vasculogenesis, endothelial cells differentiate de novo from mesodermal precursors, whereas in angiogenesis new vessels are generated from preexisting ones (Risau, 1997; Carmeliet, 2000). In embryos, both processes are essential for normal development. In adults, angiogenesis and neovascularization can be unwanted processes in certain disease states, including 
cancer and diabetic retinopathy. However, formation of new blood vessels can also help alleviate some states, as in the formation of collateral circulation in ischemic myocardium, wound healing, and endometrial regeneration. Indeed, angiogenesis and neovascularization in ischemic myocardium and limbs provide an important clinical approach (Isner et al., 1999).

Recently, several studies have examined therapeutic angiogenesis/neovascularization using growth factors as a way to treat ischemic myocardium and limbs (Takeshita et al., 1994; Isner et al., 1999; Chae et al., 2000). However, a single growth factor may be insufficient for therapeutic purposes, because the development of a functional vascular system requires a cascade of growth factors, their receptors, and intracellular signals. Of these, VEGF and Ang1 are of particular interest because their receptors are specifically located in endothelial cells (Veikkola et al., 1999; Carmeliet, 2000; Yancopoulos et al., 2000). These two factors have strong effects on angiogenesis and vasculogenesis. VEGF acts as a potent angiogenic factor, whose specific activities include endothelial cell survival, proliferation, migration, and tube formation (Ferrara et al., 1997; Veikkola et al., 1999). The biological effects of VEGF on endothelial cells are exerted through its binding to Flt-1 and Flk-1/KDR, two high affinity tyrosine kinase receptors. In the adult, VEGF is also a primary contributor to physiologic and pathologic angiogenesis through its strong biological effects on endothelial cells (Ferrara et al., 1997; Veikkola et al., 1999; Carmeliet et al., 2000). Moreover, many reports have shown that transgenic overexpression or gene transfer of VEGF increases angiogenesis and vascularization in adult tissues (Takeshita et al., 1994; Detmar et al., 1998).

Although Ang1 has no proliferative effect on endothelial cells, interestingly, transgenic overexpression or gene transfer of Ang1, but not Ang2, increases angiogenesis and vasculogenesis (Shyu et al., 1998; Suri et al., 1998; Chae et al., 2000). In a mouse corneal micropocket assay, Ang1 failed to stimulate an angiogenic response when administered alone (Asahara et al., 1998). However, when co-administered with VEGF, Ang1 augmented postnatal neovascularization. Thus, Ang1, in combination with VEGF, is a candidate for therapeutic vascularization. In a rabbit ischemic hind limb model, a combination of Ang1 and VEGF gene delivery produced an enhanced effect on blood vessel formation, resting and maximal blood flow, and capillary formation that was greater than that of either factor alone (Chae et al., 2000) (Figure 5). These results suggest that combined treatment with Ang1 and VEGF could be used to produce therapeutic vascularization. In fact, in vitro experiments indicate that Ang1 is a strong inducer of endothelial cell sprouting, secretion of plasmin and matrix metalloproteinase-2, and migration and network formation (Kim et al., 2000b). These processes are the first steps in both angiogenesis and neovascularization. These in vitro data support the role of Ang1-induced angiogenesis and vasculogenesis in vivo.

In the brain tissue of patients with brain arteriovenous malformations, Ang1 protein levels are $30 \%$ lower than in control patients, whereas Ang2 protein levels are 8fold higher than in control patients (Hashimoto et al., 2001). These patients display abnormally dilated vessels that lack mature peri-endothelial support cells. This observation suggests that Ang1 recruits and sustains periendothelial support cells, while Ang2 disrupts blood vessel formation in brain vasculogenesis. However, the mechanisms behind these processes are unknown. Nevertheless, administration of Ang1 may provide a therapeutic benefit for enhancing recruitment of peri-endothelial support cells.

\section{Therapeutic endothelial cell survival (Therapeutic Endo-survival) with Ang1}

The integrity and normal function of endothelium are indispensable for good health. In an adult human, the endothelial monolayer consists of an estimated 1 to $6 x$ $10^{13}$ cells that considered as a unit, form an approximately 1-kg heavy "organ". This "organ" plays a central role in the control of vascular tone, permeability, blood flow, coagulation, thrombolysis, inflammation, tissue repair, and growth (Cines et al., 1998). Damage to the endothelium can initiate thrombosis formation, neointimal hyperplasia, and atherogenesis (Cines et al., 1998; Stefanec, 2000). Therefore, maintaining a normal endothelial integrity in response to physical, biochemical and immune-
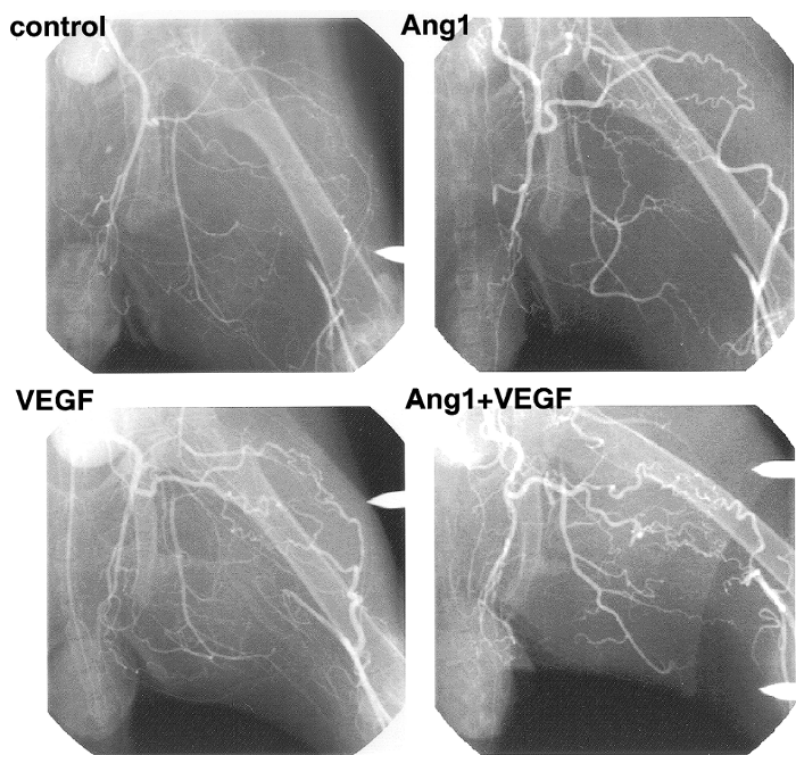

Figure 5. Representative angiographic findings of single and combined gene transfer of Ang1 and VEGF in the ischemic hind limbs of rabbits. Angiographies were performed 30 days after direct intramuscular gene transfer of (500 $\mu \mathrm{g}$ of plasmid) pControl (control), pAng1 (Ang1), pVEGF (VEGF), or pAng1 + pVEGF (Ang1+VEGF). 
mediated damage is important to prevent vascular diseases.

Interestingly, Tie2 is selectively expressed as an activated form in the endothelial cells of normal adult vessels, in which vasculogenesis and angiogenesis do not normally occur (Wong et al., 1997). We found that Ang1 is a strong survival factor for endothelial cells (Kwak et al., 2000). We also demonstrated that Ang1 induced a signal transduction pathway leading to endothelial cell survival for the first time. The Tie2 receptor, PI 3'-kinase, and Akt are crucial elements in the signal transduction pathway leading to endothelial cell survival induced by the paracrine activity of Ang1 (Kim et al., 2000c) (Figure 6). Given that Ang1 is a strong apoptosis survival factor without mitotic effect, constitutive expression of Ang1 in periendothelial cells may activate the Tie2 receptor, thereby acting as a paracrine factor that maintains normal integrity in non-proliferating endothelial cells. In fact, our in vitro experiments demonstrated that Ang1 prevented apoptosis in endothelial cells treated with several insults, including irradiation, oxidized LDL or clinical concentrations of mannitol (Kwak et al., 2000; Kim et al., 2001a). This effect was mediated through Tie2 receptor binding and PI 3'-kinase activation. In addition, Ang1 increases the survival of endothelial cells in response to lipopolysaccharide from Gram-negative bacteria. Ang1 also prevented apoptosis in endothelial cells of explanted porcine coronary arteries subjected to the same insults. Generally, Ang1's antiapoptotic potency was similar or greater than that of VEGF and bFGF.

These data suggest that systemic treatment with Ang1 could be beneficial in maintaining normal endothelial cell integrity during endothelial cell damage in vivo. Therefore, we conclude that the angiopoietin-Tie2 system is essential to the maintenance of normal endothelial survival and integrity. From this study, we coined the term 'Therapeutic endothelial cell survival

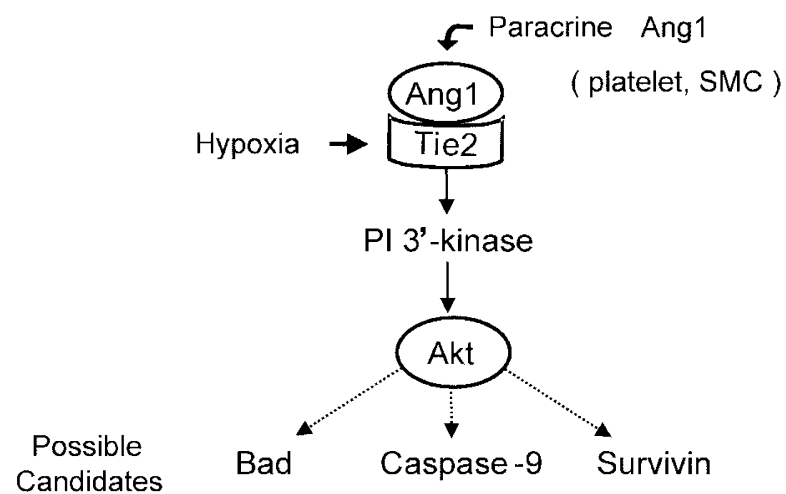

Figure 6. Ang1-induced endothelial cell survival in a paracine manner. Platelet and periendothelial smooth muscle cells produce Ang1. Ang1 binds to the Tie2 receptor, then activates the PI 3'-kinase and Akt signal transduction pathways. Downstream pathways of Akt remain to be determined, although Bad, caspase-9, and survivin are candidates.
(Therapeutic Endo-survival)' using Ang1. Although more pre-clinical study of Ang1 in vivo are warranted, Ang1 could be the most potent, selective and safe agent for therapeutic endothelial cell survival.

\section{Counteractive effect of Ang1 in VEGF-induced adhe- sion and coagulation}

VEGF acts as a proinflammatory cytokine in two ways: (1) by inducing adhesion molecules that bind leukocytes to endothelial cells and (2) by increasing endothelial permeability. These are initial and essential steps toward inflammation through the Flk-1/KDR receptor (Murohara et al., 1998; Kim et al., 2001b). In fact, the first activity attributed to VEGF was the permeabilization of microvessels, primarily postcapillary venules and small veins (Dvorak et al., 1995). Although VEGF overexpressed in mouse skin increases vascularity, the vascularized skin shows signs of inflammation, including vascular leakage, edema, and increased adhesion of leukocytes (Detmar et al., 1998). Ang1 overexpressed in mouse skin results in a prominent enlargement of vessels without signs of inflammation (Suri et al., 1998; Thurston et al., 1999). Moreover, when co-overexpressed in mouse skin, VEGF and Ang 1 show an additive effect on angiogenesis, but result in leakage-resistant vessels with little inflammation (Thurston et al., 1999). Systemic adenoviral delivery of Ang1 does indeed protect adult blood vasculature from leaking (Thurston et al., 2000).

It appears that Ang1 counteracts at least some component of VEGF activity in endothelial cells during certain pathologic conditions. Furthermore, a recent in vitro experiment demonstrated that Ang1 decreases Eselectin expression and decreases basal and VEGFinduced endothelial permeability, possibly through the regulation of junctional complexes, platelet endothelial cell adhesion molecule-1, and vascular endothelial cadherin (Gamble et al., 2000). In addition, Ang1 suppressed VEGF-induced expression of several adhesion molecules, such as intercellular adhesion molecule-1, vascular cell adhesion molecule-1, and E-selectin (Kim et al., 2001c). Furthermore, Ang1 reduced VEGF-induced leukocyte adhesion to HUVECs (Kim et al., 2001c). Thus, Ang1 counteracts VEGF-induced inflammation by reducing VEGF-induced endothelial adhesiveness. Taken together, Ang1 counteracts VEGF-induced inflammation in endothelial cells, while having an additive effect on vessel formation (Figure 7). Therefore, combined treatment with VEGF and Ang1 could be better than single treatment for enhancing therapeutic vascularization and angiogenesis, while avoiding inflammation.

VEGF, like TNF- $\alpha$, can act as a procoagulant cytokine by increasing tissue factor (TF) expression in endothelial cells (Mechtcherakova et al., 1999). Ang1 counteracts VEGF-induced expression and activity of TF, possibly through the activation of the $\mathrm{PI} 3^{\prime}$-kinase/Akt pathway 

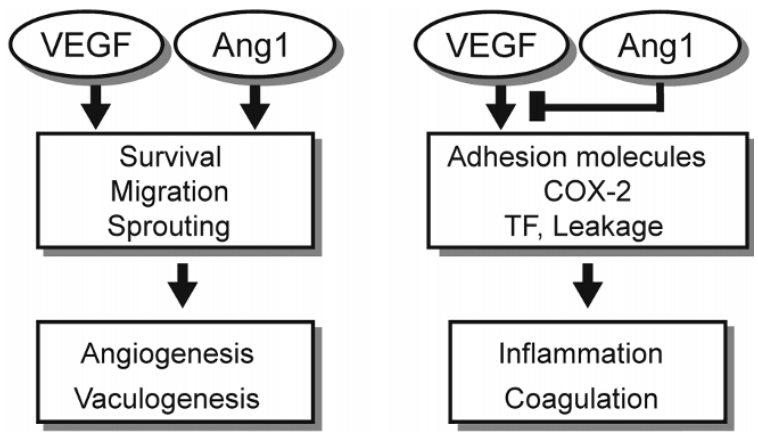

Figure 7. Interactive and counteractive effect of VEGF and Ang1 in endothelial cells. VEGF and Ang1 produce an additive or synergistic effect on survival, migration, and sprouting. In contrast, Ang1 counteracts VEGFinduced inflammation and coagulation through suppression of VEGFinduced vascular leakage and suppression of VEGF-induced expression of adhesion molecules, COX-2 and tissue factor.

(Kim et al., 2002). These results suggest that Ang1 may be used as an inhibitor of VEGF-induced coagulation, inflammation, and tumor-associated angiogenesis and metastasis by suppression of TF expression.

\section{Problems and future directions}

It is now quite clear that understanding of the angiopoietin-Tie2 system is important not only in vascular biology but also in several biomedical fields. However, the following problems must be solved to pave the way for future research and clinical applications.

First, Ang1 protein is not easily available because generation of recombinant Ang1 is extremely difficult with current techniques. Since Ang1 has long coiled-coil domains at the $\mathrm{N}$-terminal end, it is not soluble, aggregates easily, and sticks to everything during its generation and purification. Therefore, Ang ${ }^{*}$ was generated by Regeneron Pharmaceuticals, Inc. Ang1* is a recombinant version of Ang1 that is easier to produce and purify (Maisonpierre et al., 1997). Ang1* contains a modified $\mathrm{NH}_{2}$-terminus and mutated Cys ${ }^{245}$. The Cys ${ }^{245}$ residue is not shared between Ang1 and Ang2, and its mutation does not alter Ang1's agonistic properties. The biological activity of recombinant Ang1 and Ang1* is similar. However, the generation of Ang $1^{*}$ has some of the same problems. It may be possible to develop a chimeric Ang1 containing a minimum coiled-coil domain, just long enough for dimerization. But it would need to have equivalent potency compared to native Ang1.

Second, we still do not know the molecular and cellular mechanism by which Ang1 recruits pericytes to the endothelial cells through Tie2. It would be valuable if we knew what molecules are secreted from Ang1activated endothelial cells during pericyte recruitment.

Third, combined treatment with Ang1 and VEGF for therapeutic vessel formation should be developed. For therapeutic vessel formation, VEGF has been tested extensively, and it is already in clinical trials. Meanwhile Ang1 is still being tested in animals. Although the exact molecular mechanism by which Ang1 inhibits VEGFinduced vascular permeability, inflammation, and coagulation remains to be determined, we have ample evidence that Ang1 can counteract the unwanted side effects of VEGF in certain situations, while Ang1 produces an enhanced effect on therapeutic vessel formation.

Fourth, use of Ang1 should be demonstrated in experimental animal models. It would be worthwhile to try an acute administration of Ang1 for maintaining endothelial integrity during an insult, such as, angioplasty, irradiation, sepsis, or mannitol treatment. These experiments will tell us if Ang1 has any beneficial effects in vivo.

Fifth, the use of Ang1 for other clinical applications should be developed. For example, clinical trials are underway to test use of Ang1 for preventing vascular leakage in diabetic retinopathy. We also demonstrated that therapeutic endothelial cell survival with Ang1 would provide clinical benefits. Pre-clinical investigations for therapeutic endothelial cell survival should be developed.

In conclusion, more work is needed in the future, but clearly the results already show that angiopoietin is very important in vascular biology and medicine.

\section{Acknowledgements}

The authors thank the members of National Creative Research Initiatives Center for Endothelial Cells, Pohang University of Science and Technology. This work was supported by the Creative Research Initiatives of the Korean Ministry of Science and Technology and by the Brain Korea 21 Project.

\section{References}

Asahara T, Chen D, Takahashi T, Fujikawa K, Kearney M, Magner M, Yancopoulos GD, Isner JM. Tie2 receptor ligands, angiopoietin-1 and angiopoietin-2, modulate VEGF-induced postnatal neovascularization. Circ Res 1998;83:233-40

Brown LF, Dezube BJ, Tognazzi K, Dvorak HF, Yancopoulos GD. Expression of Tie1, Tie2, and angiopoietins 1, 2, and 4 in Kaposi's sarcoma and cutaneous angiosarcoma. Am J Pathol 2000;156:2179-83

Bunone G, Vigneri P, Mariani L, Buto S, Collini P, Pilotti S, Pierotti MA, Bongarzone I. Expression of angiogenesis stimulators and inhibitors in human thyroid tumors and correlation with clinical pathological features. Am J Pathol 1999;155: 1967-76

Carmeliet P. Mechanisms of angiogenesis and arteriogenesis. Nature Med 2000;6:389-95 
Carmeliet P, Ferreira V, Breier G, Pollefeyt S, Kieckens L, Gertsenstein M, Fahrig M, Vandenhoeck A, Harpal K, Eberhardt C, Declercq C, Pawling J, Moons L, Collen D, Risau W, Nagy A. Abnormal blood vessel development and lethality in embryos lacking a single VEGF allele. Nature 1996;380:435-39

Carmeliet P, Jain RK. Angiogenesis in cancer and other diseases. Nature 2000;407:249-57

Chae JK, Kim I, Lim ST, Chung MJ, Kim WH, Kim HG, Ko JK, Koh GY. Co-administration of angiopoietin-1 and vascular endothelial growth factor enhances collateral vascularization. Arterioscler Thromb Vasc Biol 2000;20:2573-78

Cines DB, Pollak ES, Buck CA, Loscalzo J, Zimmerman GA, McEver RP, Pober JS, Wick TM, Konkle BA, Schwartz BS, Barnathan ES, McCrae KR, Hug BA, Schmidt AM, Stern DM. Endothelial cells in physiology and in the pathophysiology of vascular disorders. Blood 1998;91:3527-61

Cohen B, Barkan D, Levy Y, Goldberg I, Fridman E, Kopolovic $J$, Rubinstein M. Leptin induces angiopoietin-2 expression in adipose tissues. J Biol Chem 2001;276:7697-700

Davis S, Aldrich TH, Jones PF, Acheson A, Compton DL, Jain $\mathrm{V}$, Ryan TE, Bruno J, Radziejewski C, Maisonpierre PC, Yancopoulos GD. Isolation of angiopoietin-1, a ligand for the TIE2 receptor by secretion-trap expression cloning. Cell 1996; 87:1161-69

Detmar M, Brown LF, Schon MP, Elicker BM, Velasco P, Richard L, Fukumura D, Monsky W, Claffey KP, Jain RK. Increased microvascular density and enhanced leukocyte rolling and adhesion in the skin of VEGF transgenic mice. J Invest Dermatol 1998;111:1-6

Dias S, Heissig B, Hackett NR, Lyden D, Tateno M, Hicklin DJ, Zhu Z, Witte L, Crystal RG, Moore MA, Rafii S. Vascular endothelial growth factor and angiopoietin-1 stimulate postnatal hematopoiesis by recruitment of vasculogenic and hematopoietic stem cells. J Exp Med 2001;193:1005-14

Dumont DJ, Gradwohl GJ, Fong GH, Auerbach R, Breitman ML. The endothelial-specific receptor tyrosine kinase, tek, is a member of a new subfamily of receptors. Oncogene 1993;8: 1293-301

Dunk C, Shams M, Nijjar S, Rhaman M, Qiu Y, Bussolati B, Ahmed A. Angiopoietin-1 and angiopoietin-2 activate trophoblast Tie-2 to promote growth and migration during placental development. Am J Pathol 2000;156:2185-99

Dvorak HF, Brown LF, Detmar M, Dvorak AM. Vascular permeability factor/vascular endothelial growth factor, microvascular hyperpermeability, and angiogenesis. Am J Pathol 1995;146:1029-39

Etoh T, Inoue H, Tanaka S, Barnard GF, Kitano S, Mori M. Angiopoietin-2 is related to tumor angiogenesis in gastric carcinoma: possible in vivo regulation via induction of proteases. Cancer Res 2001;61:2145-53

Ferrara N, Davis-Smyth T. The biology of vascular endothelial growth factor. Endocrine Rev 1997;18:4-25

Fujiyama S, Matsubara H, Nozawa Y, Maruyama K, Mori Y, Tsutsumi Y, Masaki H, Uchiyama Y, Koyama Y, Nose A, Iba O, Tateishi E, Ogata N, Jyo N, Higashiyama S, Iwasaka T.
Angiotensin AT(1) and AT(2) receptors differentially regulate angiopoietin-2 and vascular endothelial growth factor expression and angiogenesis by modulating heparin binding-epidermal growth factor (EGF)-mediated EGF receptor transactivation. Circ Res 2001;88:22-29

Gamble JR, Drew J, Trezise L, Underwood A, Parsons M, Kasminkas L, Rudge J, Yancopoulos G, Vadas MA. Angiopoietin-1 is an antipermeability and anti-inflammatory agent in vitro and targets cell junctions. Circ Res 2000;87:603-7

Geva E, Jaffe RB. Role of angiopoietins in reproductive tract angiogenesis. Obstet Gynecol Surv 2000;55:511-19

Goede V, Schmidt T, Kimmina S, Kozian D, Augustin HG. Analysis of blood vessel maturation processes during cyclic ovarian angiogenesis. Lab Invest 1998;78:1385-94

Goldman-Wohl DS, Ariel I, Greenfield C, Lavy Y, Yagel S. Tie2 and angiopoietin-2 expression at the fetal-maternal interface: a receptor ligand model for vascular remodelling. Mol Hum Reprod 2000;6:81-87

Hashimoto T, Lam T, Boudreau NJ, Bollen AW, Lawton MT, Young WL. Abnormal balance in the angiopoietin-tie2 system in human brain arteriovenous malformations. Circ Res 2001; 89:111-13

Hayes AJ, Huang WQ, Yu J, Maisonpierre PC, Liu A, Kern FG, Lippman ME, McLeskey SW, Li LY. Expression and function of angiopoietin-1 in breast cancer. $\mathrm{Br} \mathrm{J}$ Cancer 2000;83:1154-60

Holash J, Maisonpierre PC, Compton D, Boland P, Alexander CR, Zagzag D, Yancopoulos GD, Wiegand SJ. Vessel cooption, regression, and growth in tumors mediated by angiopoietins and VEGF. Science 1999;284:1994-98

Huang YQ, Li JJ, Karpatkin S. Identification of a family of alternatively spliced mRNA species of angiopoietin-1. Blood 2000;95:1993-99

Isner JM, Asahara T. Angiogenesis and vasculogenesis as therapeutic strategies for postnatal neovascularization. J Clin Invest 1999;103:1231-36

Iwama A, Hamaguchi I, Hashiyama M, Murayama Y, Yasunaga K, Suda T. Molecular cloning and characterization of mouse TIE and TEK receptor tyrosine kinase genes and their expression in hematopoietic stem cells. Biochem Biophys Res Commun 1993;195:301-9

Jones N, Dumont DJ. The Tek/Tie2 receptor signals through a novel Dok-related docking protein, Dok-R. Oncogene 1998; 17:1097-108

Jones N, Master Z, Jones J, Bouchard D, Gunji Y, Sasaki H, Daly R, Alitalo K, Dumont DJ. Identification of Tek/Tie2 binding partners. Binding to a multifunctional docking site mediates cell survival and migration. J Biol Chem 1999;274:30896-905

Kim I, Kim HG, Kim H, Kim HH, Park SK, Uhm CS, Lee ZH, Koh GY. Hepatic expression, synthesis and secretion of novel angiopoietin-related protein prevents endothelial cell apoptosis. Biochemical J 2000a;346:603-10

Kim I, Kim HG, Moon SO, Chae SW, So JN, Koh KN, Ahn BC, Koh GY. Angiopoietin-1 induces endothelial cell sprouting 
through the activation of focal adhesion kinase and plasmin secretion. Circ Res 2000b;86:952-59

Kim I, Kim HG, So JN, Kim JH, Kwak HJ, Koh GY. Angiopoietin-1 regulates endothelial cell survival through the phosphatidylinositol 3'-Kinase/Akt signal transduction pathway. Circ Res 2000c;86:24-29

Kim I, Kim JH, Moon SO, Kwak HJ, Kim NG, Koh GY. Angiopoietin-2 at high concentration can enhance endothelial cell survival through the phosphatidylinositol 3'-kinase/Akt signal transduction pathway. Oncogene 2000d;19:4549-52

Kim I, Kim JH, Ryu YS, Jung SH, Nah JJ, Koh GY. Characterization and expression of a novel alternatively spliced human angiopoietin-2. J Biol Chem 2000e;275:18550-56

Kim I, Kim JH, Ryu YS, Liu M, Koh GY. Tumor necrosis factoralpha upregulates angiopoietin-2 in human umbilical vein endothelial cells. Biochem Biophys Res Commun 2000f;269: 361-65

Kim I, Kwak HJ, Moon SO, Oh JL, Koh GY. Angiopoietin-1 inhibits VEGF-induced tissue factor mRNA and proteins through PI 3'-kinase/Akt activation in endothelial cells. FASEB J 2002;16:126-28 (on line supplement 10.1096/fj.01-0556fje)

Kim I, Moon SO, Kim SH, Kim HJ, Koh YS, Koh GY. VEGF stimulates expression of ICAM-1, VCAM-1 and E-Selectin through nuclear factor- $\mathrm{\kappa B}$ activation in endothelial cells. J Biol Chem 2001b;276:7614-20

Kim I, Moon SO, Koh KN, Kim H, Kwak HJ, Koh GY. Molecular cloning, expression and characterization of angiopoietin-related protein. J Biol Chem 1999;274:26523-28

Kim I, Moon SO, Han CY, Kim PY, Moon SK, Kim JJ, Koh GY. The angiopoietin-Tie2 System in coronary artery endothelium prevents oxidized low-density lipoprotein-induced apoptosis. Cardiovas Res 2001a;49:872-81

Kim I, Moon SO, Park SK, Chae SW, Koh GY. Angiopoietin1 reduces VEGF-stimulated leukocyte adhesion to endothelial cells by reducing ICAM-1, VCAM-1, and E-Selectin expression. Circ Res 2001c;89:477-79

Kontos CD, Stauffer TP, Yang WP, York JD, Huang L, Blanar MA, Meyer T, Peters KG. Tyrosine 1101 of Tie2 is the major site of association of p85 and is required for activation of phosphatidylinositol 3'-kinase and Akt. Mol Cell Biol 1998;18: 4131-40

Korpelainen El, Karkkainen M, Gunji Y, Vikkula M, Alitalo K. Endothelial receptor tyrosine kinases activate the STAT signaling pathway: mutant Tie-2 causing venous malformations signals a distinct STAT activation response. Oncogene 1999; 18:1-8

Kwak HJ, So J-N, Lee SJ, Kim I, Koh GY. Angiopoietin-1 is an apoptosis survival factor for endothelial cells. FEBS Lett 1999;448:249-53

Kwak HJ, Lee SJ, Lee YH, Ryu CH, Koh KN, Choi HY, Koh GY. Angiopoietin-1 inhibits radiation-, and mannitol-induced apoptosis in endothelial cells. Circulation 2000;101:2317-24

Lin P, Buxton JA, Acheson A, Radziejewski C, Maisonpierre PC, Yancopoulos GD, Channon KM, Hale LP, Dewhirst MW,
George SE, Peters KG. Antiangiogenic gene therapy targeting the endothelium-specific receptor tyrosine kinase Tie2. Proc Natl Acad Sci USA 1998;95:8829-34

Maisonpierre PC, Suri C, Jones PF, Bartunkova S, Wiegand SJ, Radziejewski C, Compton D, McClain J, Aldrich TH, Papadopoulos N, Daly TJ, Davis S, Sato TN, Yancopoulos GD. Angiopioetin-2, a natural antagonist for Tie2 that disrupts in vivo angiogenesis. Science 1997;277:55-60

Mandriota SJ, Pepper MS. Regulation of angiopoietin-2 mRNA levels in bovine microvascular endothelial cells by cytokines and hypoxia. Circ Res 1998;83:852-59

Mandriota SJ, Pyke C, Di Sanza C, Quinodoz P, Pittet B, Pepper MS. Hypoxia-inducible angiopoietin-2 expression is mimicked by iodonium compounds and occurs in the rat brain and skin in response to systemic hypoxia and tissue ischemia. Am J Pathol 2000;156:2077-89

Master Z, Jones N, Tran J, Jones J, Kerbel RS, Dumont DJ. Dok-R plays a pivotal role in angiopoietin-1-dependent cell migration through recruitment and activation of Pak. EMBO J 2001;20:5919-28

Mechtcheriakova D, Wlachos A, Holzmuller H, Binder BR, Hofer E. Vascular endothelial cell growth factor-induced tissue factor expression in endothelial cells is mediated by EGR-1. Blood 1999;93:3811-23

Murohara T, Horowitz JR, Silver M, Tsurumi $\mathrm{Y}$, Chen D, Sullivan A, Isner JM. Vascular endothelial growth factor/ vascular permeability factor enhances vascular permeability via nitric oxide and prostacyclin. Circulation 1998;97:99-107

Mustonen T, Alitalo K. Endothelial receptor tyrosine kinases involved in angiogenesis. J Cell Biol 1995;129:895-98

Oh H, Takagi H, Suzuma K, Otani A, Matsumura M, Honda Y. Hypoxia and vascular endothelial growth factor selectively upregulate angiopoietin-2 in bovine microvascular endothelial cells. J Biol Chem 1999;274:15732-39

Otani A, Takagi H, Oh H, Koyama S, Honda Y. Angiotensin II induces expression of the Tie2 receptor ligand, angiopoietin2 , in bovine retinal endothelial cells. Diabetes 2001;50:867-75

Phillips RL, Ernst RE, Brunk B, Ivanova N, Mahan MA, Deanehan JK, Moore KA, Overton GC, Lemischka IR. The genetic program of hematopoietic stem cells. Science 2000; 288:1635-40

Rajantie I, Ekman N, lljin K, Arighi E, Gunji Y, Kaukonen J, Palotie A, Dewerchin M, Carmeliet P, Alitalo K. Bmx tyrosine kinase has a redundant function downstream of angiopoietin and vascular endothelial growth factor receptors in arterial endothelium. Mol Cell Biol 2001;21:4647-55

Risau W. Mechanisms of angiogenesis. Nature 1997;386:67174

Sato TN, Tozawa Y, Deutsch U, Wolburg-Buchholz K, Fujiwara Y, Gendron-Maguire M, Gridley T, Wolburg H, Risau W, Qin Y. Distinct roles of the receptor tyrosine kinases Tie-1 and Tie-2 in blood vessel formation. Nature 1995;376:70-74

Shim WS, Teh M, Mack PO, Ge R. Inhibition of angiopoietin1 expression in tumor cells by an antisense RNA approach 
inhibited xenograft tumor growth in immunodeficient mice. Int J Cancer 2001;94:6-15

Shyu KG, Manor O, Magner M, Yancopoulos GD, Isner JM. Direct intramuscular injection of plasmid DNA encoding angiopoietin-1 but not angiopoietin-2 auguments revascularization in the rabbit ischemic hindlimb. Circulation 1998;98:2081-87

Stefanec T. Endothelial apoptosis: Could it have a role in the pathogenesis and treatment of disease? Chest 2000;117:84154

Stratmann A, Risau W, Plate KH. Cell type-specific expression of angiopoietin-1 and angiopoietin-2 suggests a role in glioblastoma angiogenesis. Am J Pathol 1998;153:1459-66

Suri C, Jones PF, Patan S, Bartunkova S, Maisonpierre PC, Davis S, Sato TN, Yancopoulos GD. Requisite role of angiopoietin-1, a ligand for the TIE2 receptor, during embryonic angiogenesis. Cell 1996;87:1171-80

Suri C, McClain J, Thurston G, McDonald DM, Zhou H, Oldmixon EH, Sato TN, Yancopoulos GD. Increased vascularization in mice overexpressing angiopoietin-1. Science 1998;282:468-71

Takahama M, Tsutsumi M, Tsujiuchi T, Nezu K, Kushibe K, Taniguchi S, Kotake Y, Konishi Y. Enhanced expression of Tie2, its ligand angiopoietin-1, vascular endothelial growth factor, and CD31 in human non-small cell lung carcinomas. Clin Cancer Res 1999;5:2506-10

Takakura N, Huang XL, Naruse T, Hamaguchi I, Dumont DJ, Yancopoulos GD, Suda T. Critical role of the TIE2 endothelial cell receptor in the development of definitive hematopoiesis. Immunity 1998;9:677-86

Takakura N, Watanabe T, Suenobu S, Yamada Y, Noda T, Ito Y, Satake M, Suda T. A role for hematopoietic stem cells in promoting angiogenesis. Cell 2000;102:199-209

Takeshita S, Zheng LP, Brogi E, Kearney M, Pu LQ, Bunting $S$, Ferrara N, Symes SF, Isner JM. Therapeutic angiogenesis: a single intra-arterial bolus of vascular endothelial growth factor augments revascularization in a rabbit ischemic hindlimbmodel. J Clin Invest 1994;93:662-70

Thurston G, Rudge JS, loffe E, Zhou H, Ross L, Croll SD,
Glazer N, Holash J, McDonald DM, Yancopoulos GD. Angiopoietin-1 protects the adult vasculature against plasma leakage. Nat Med 2000;6:460-63

Thurston G, Suri C, Smith K, McClain J, Sato TN, Yancopoulos GD, McDonald DM. Leakage-resistant blood vessels in mice transgenically overexpressing angiopoietin-1. Science 1999;286:2511-14

Valenzuela DM, Griffiths JA, Rojas J, Aldrich TH, Jones PF, Zhou H, McClain J, Copeland NG, Gilbert DJ, Jenkins NA, Huang T, Papadopoulos N, Maisonpierre PC, Davis S, Yancopoulos GD. Angiopoietins 3 and 4: diverging gene counterparts in mice and humans. Proc Natl Acad Sci USA 1999;96:1904-9

van der Geer P, Hunter T, Lindberg RA. Receptor proteintyrosine kinases and their signal transduction pathways. Annu Rev Cell Biol 1994;10:251-37

Veikkola T, Alitalo K. VEGFs, receptors and angiogenesis. Seminars in Cancer Biol 1999;9:211-20

Wong AL, Haroon ZA, Werner S, Dewhirst MW, Greenberg CS, Peters KG. Tie2 expression and phosphorylation in angiogenic and quiescent adult tissues. Circ Res 1997;81:567-74

Yancopoulos GD, Davis S, Gale NW, Rudge JS, Wiegand SJ, Holash J. Vascular-specific growth factors and blood vessel formation. Nature 2000;407:242-48

Yoshida Y, Oshika Y, Fukushima Y, Tokunaga T, Hatanaka H, Kijima $H$, Yamazaki $H$, Ueyama $Y$, Tamaoki N, Miura S, Nakamura M. Expression of angiostatic factors in colorectal cancer. Int J Oncol 1999;15:1221-25

Yu Y, Varughese J, Brown LF, Mulliken JB, Bischoff J. Increased Tie2 expression, enhanced response to angiopoietin1 , and dysregulated angiopoietin-2 expression in hemangiomaderived endothelial cells. Am J Pathol 2001;159:2271-80

Zagzag D, Hooper A, Friedlander DR, Chan W, Holash J, Wiegand SJ, Yancopoulos GD, Grumet M. In situ expression of angiopoietins in astrocytomas identifies angiopoietin-2 as an early marker of tumor angiogenesis. Exp Neurol 1999; $159: 391-400$ 